\begin{tabular}{c} 
International Journal of Basic and Applied Sciences, 5 (4) (2016) 196-199 \\
International Journal of Basic and Applied Sciences \\
Website $\begin{array}{c}\text { www.sciencepubco.com/index.php/IJBAS } \\
\text { doi: } 10.14419 / \text { ijbas.v5i4.5739 } \\
\text { Research paper }\end{array}$ \\
\hline
\end{tabular}

\title{
Photo-acoustic properties of nanoTiO2:Er
}

\author{
R. Palomino-Merino ${ }^{1 *}$, R. Lozada-Morales ${ }^{1}$, J. Martínez-Juárez ${ }^{1}$, G. Juárez-Díaz ${ }^{1}$, J. Carmona-Rodriguez ${ }^{1}$, P. \\ Del Angel $^{2}$, S. Jiménez-Sandoval ${ }^{3}$, S. A. Tomas ${ }^{3}$, O. Zelaya-Angel ${ }^{3}$, V. M. Castaño ${ }^{4 *}$ \\ ${ }^{1}$ Benemérita Universidad Autónoma de Puebla. 14 Av. Sur y Av. San Claudio, Col. San Manuel. 72570 Puebla, México. aPosgrado en \\ Física Aplicada, Facultad de Ciencias Físico-Matemáticas. BDepartamento de Dispositivos Semiconductores. \\ ${ }^{2}$ Subdivisión Investigación Científica Aplicada, Instituto Mexicano del Petróleo, P.O. Box 14-805, México 07730 D.F. \\ ${ }^{3}$ Centro de Investigación y de Estudios Avanzados del IPN. cLaboratorio de Investigación en Materiales, Unidad Querétaro, Apdo. \\ Postal 1-798, Querétaro76001, México. dDepartamento de Física, P.O. Box 14-740, México 07360 D.F. \\ ${ }^{4}$ Centro de Física Aplicada y Tecnología Avanzada, U.N.A.M Boulevard Juriquilla 3001 Santiago de Querétaro, Querétaro 76230. \\ *Corresponding authorE-mail: palomino@fcfm.buap.mx, meneses@unam.mx
}

\begin{abstract}
Nanocrystalline Er-doped TiO2 was prepared by sol-gel at room temperature. X-ray diffraction, photoacoustic spectroscopy (optical absorption), transmission electron microscopy (TEM), and electron dispersion microscopy (EDS) were carried out on both as-prepared and thermally-annealed (air at $700{ }^{\circ} \mathrm{C}$ ) samples, revealing the anatase crystalline phase of $\mathrm{TiO} 2$. The samples exhibit an average grain size from 38 to $5.1 \mathrm{~nm}$, as the nominal concentration of Er varies from $0 \%$ to $7 \%$. The photoacoustic spectra evidence the absorption edge at $300 \mathrm{~nm}$ attributed to $\mathrm{TiO} 2$, as well as several electronic transitions which are atomic energy absorption-line levels characteristics of Er.
\end{abstract}

Keywords: Titanium Dioxide; Crystal Morphology; Doping; Nanomaterials; Dielectric Materials Semicolon.

\section{Introduction}

Titania $\left(\mathrm{TiO}_{2}\right)$ is a widely used due to its important optical, chemical and mechanical properties. Applications range from gas and/or humidity sensor, catalyst, optical coatings, to photovoltaic cells and rechargeable batteries, among many other [1-5]. To improve its optical performance, dye sensitization of $\mathrm{TiO}_{2}$ has been performed towards a more efficient harvesting of optical energy, by absorbing light within a wider electromagnetic range [6-9]. Nanocrystalline $\mathrm{TiO}_{2}$ represents an important alternative for most of the aforementioned applications and the sol-gel technique offers a suitable and economic route in the synthesis of $\mathrm{TiO}_{2}$ [10], [11] and, most important, the synthesis of titania with adequate optical probes included in the bulk.

Accordingly, in this work nanocrystalline Er-doped $\mathrm{TiO}_{2}$ synthetized by sol-gel from titanium isopropoxide $\left(\mathrm{Ti}\left(\mathrm{OC}_{3} \mathrm{H}_{7}\right)_{4}\right)$ as precursor, with thermal annealing in air, is reported. Physical properties of the nanotitania are discussed as function of the Er content and particle size. This material has potential applications photocatalysis and energy storage, as shall be discussed.

\section{Experimental}

Nanocrystalline titania (NT) was prepared by mixing, at room temperature (RT), $1.0 \mathrm{~mol}$ of titanium isopropoxide (TIPO) (Aldrich) with $2.0 \mathrm{~mol}$ of acetic acid (Aldrich) and $2.0 \mathrm{~mol}$ of isopropanol (Baker) under stirring. Separately, $0.5 \mathrm{~mol}$ of $\mathrm{Er}\left(\mathrm{NO}_{3}\right)_{3} .3 \mathrm{H}_{2} \mathrm{O}$ (Aldrich) was dissolved in a mixture of $2.0 \mathrm{~mol}$ of water, $2.0 \mathrm{~mol}$ of propanol and $2.0 \mathrm{~mol}$ of acetic acid. Subsequently, both solutions were mixed under vigorous agitation. Titania sols doped with $0.01,0.03,0.04,0.05,0.06$ and 0.07 molar con- centrations of Er were so obtained. After two months of gelation the samples were thermally annealed in air at $700{ }^{\circ} \mathrm{C}$ for 1 hour. A Siemens D-5000 powder diffractometer using the $\mathrm{CuK}_{\alpha}$ radiation was employed. Optical absorption was measured with a home-made photoacoustic spectrometer, equipped with a Xe lamp (Oriel), a monochromator (Oriel), a mechanical chopper (Oriel) held at $17 \mathrm{~Hz}$, and a closed photoacoustic cell. A D/Max2100 Rigaku Transmission Electron Microscopy (TEM) was used. Semi-quantitative measurements of atomic concentration of $\mathrm{Ti}, \mathrm{O}$, and Er elements were achieved by electron dispersion spectroscopy (EDS), utilizing a Voyager II X-ray quantitative microanalysis in an 1100/1110 EDX system, from Noran Instruments.

\section{Results and discussion}

The atomic percentage (at \%) of $\mathrm{Er}$ in $\mathrm{nTiO}_{2}$, measured by EDS, vs. the nominal concentration (in percentage units) of $\mathrm{Er}$ [NEr] in the growing solution is displayed in Fig. 1. 


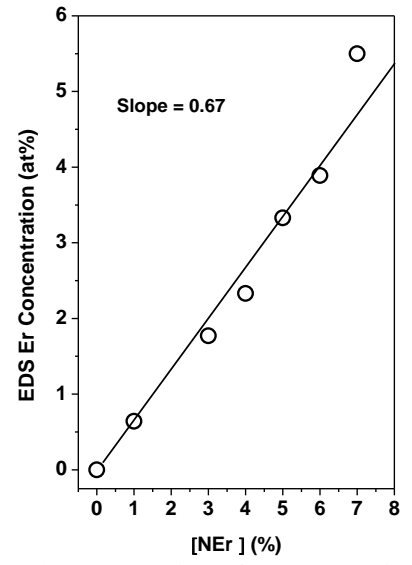

Fig. 1: EDS Measured Concentration of Er vs. Nominal [Ner] Concentration of Er in the Growing Precursor Solution.

A linear behavior is observed for the whole range of [NEr] studied. The solid line represents the linear least square fitting to the data. The slope of the straight line is $0.67 \pm 0.04$, which indicates that, in general, only $2 / 3$ of the nominal Er percentage is observed in each sample. The remaining $1 / 3$ is probably sublimated during the gelation and/or the thermal annealing at $700{ }^{\circ} \mathrm{C}$. Figure 2 shows the X-ray diffraction (XRD) patterns, in the $2 \theta$ range $10^{\circ}$ $75^{\circ}$ of all the samples. The material exhibits the anatase crystalline structure of $\mathrm{TiO}_{2}$; some peaks reveal the presence of small amounts of rutile and brookite phases of $\mathrm{TiO}_{2}$, only in the undoped sample [12]

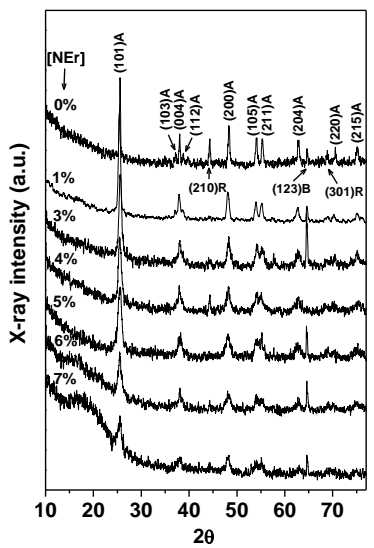

Fig. 2: X-Ray Diffraction Patterns for All the [Ner] Contents. A, B and R Letters Attached to the Indexes on XRD-Peaks Denotes Anatase, Brookite And Rutile, Respectively.

Reflections due to Er and Er-oxides were not observed, as in $\mathrm{nTiO}_{2}$ : Er nanoparticles reported by other authors [13]. The XRD peaks broaden with the Er content, which is consequence of the size reduction of particles as more $\mathrm{Er}$ is incorporated into the $\mathrm{TiO}_{2}$. Figure 3 shows a typical TEM image of the $\mathrm{nTiO}_{2}$ prepared with $5 \%$ [Er] sample, revealing an averge grain size of $5 \mathrm{~nm}$.

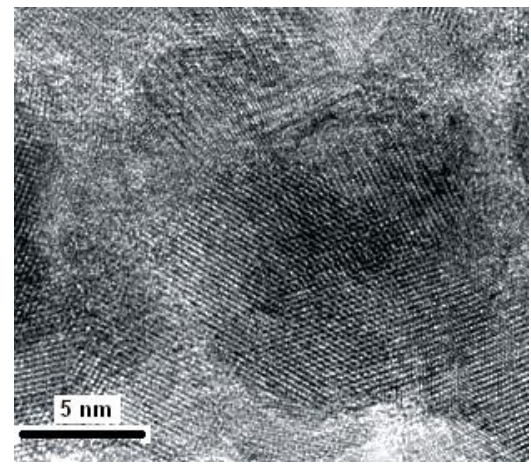

Fig. 3: Transmission Electron Microscopy Image of The Sample with $[\mathrm{Ner}]=5$ at $\%$. The Black Bar at the Down-Left Corner Corresponds to 5 $\mathrm{Nm}$.
The optical absorption (OA) spectra, measured by using photoacoustic (PA) spectroscopy, in the range $1.5-4.0 \mathrm{eV}$ range, are presented in Figure 4 for all the samples.

The advantage of using the PA spectroscopy for OA measurements is that it is less sensitive to light scattering effects than conventional optical techniques [14]. The spectra evidence an absorption edge at a wavelength of around $3.0 \mathrm{eV}$ and six electronic transitions, which indicate some well-defined Er atomic energy absorption levels. The six electronic transitions, identified with triply ionized erbium ions, are ${ }^{4} \mathrm{I}_{9 / 2},{ }^{4} \mathrm{~F}_{9 / 2},{ }^{4} \mathrm{~S}_{3 / 2},{ }^{2} \mathrm{H}_{11 / 2}$, and ${ }^{4} \mathrm{~F}_{3 / 2}$, all of them are transitions until the ground level ${ }^{4} \mathrm{I}_{15 / 2}$ [15]. The inset in Figure 4 displays how the ${ }^{4} \mathrm{~S}_{3 / 2}$ level is resolved from the ${ }^{2} \mathrm{H}_{11 / 2}$ by a deconvolution procedure.

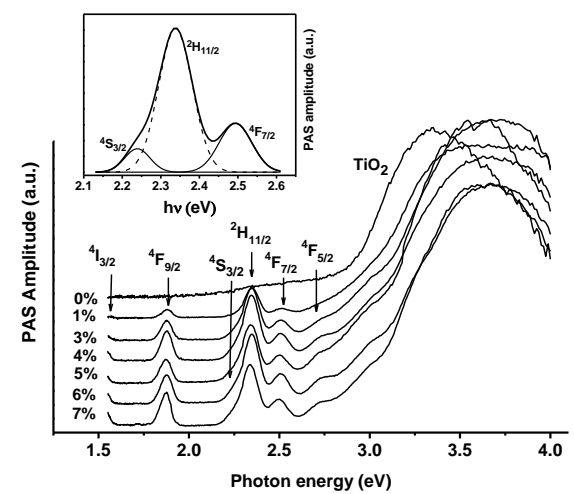

Fig. 4: Photoacoustical Optical Absorption Spectra (PAS) for All the [Ner] Values Analyzed. the Inset Describes the Deconvolution Process Applied to Resolve the ${ }^{4} \mathrm{~S}_{3 / 2}$ and ${ }^{2} \mathrm{H}_{11 / 2}$ Emissions.

Figure 5 exhibits the nanoparticle average grain size (GS) as a function of [NEr], calculated from the Scherrer formula by considering, as an approximation, a spherical shape of the grains. It can be observed that GS decreases when $[\mathrm{NEr}]$ increases.

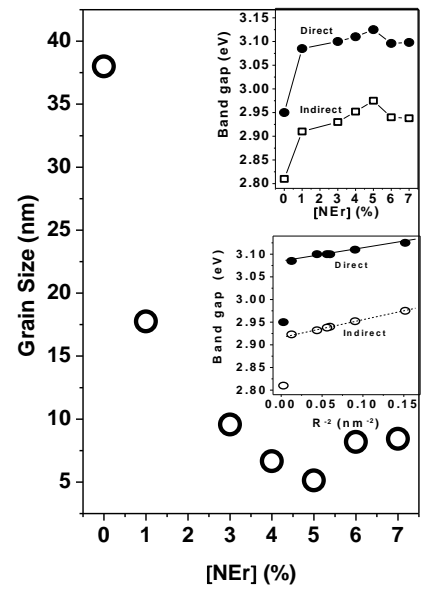

Fig. 5: Grains Size as a Function of [Ner]. The Top Inset Displays the Direct and the Indirect Energy Band Gaps Vs [Ner]. The Bottom Inset (A) Displays $\mathrm{E}_{\mathrm{gd}}$ and $\mathrm{E}_{\mathrm{gi}}$ Vs. The Inverse Radius Square of the Nanoparticle. the Solid and Dotted Lines are Least Square Fitting of the Data.

Bahtat and co-workers have suggested that $\mathrm{Er}^{3+}$ strongly affects the crystallization of sol-gel-based titania by stabilizing amorphous material [16]. Then, in our case, Er and thermal annealing of $\mathrm{TiO}_{2}$ samples produced nanocrystalline grains, whose average diameter depended on [NEr] and on the annealing temperature values chosen that, in this work, was $700{ }^{\circ} \mathrm{C}$. A minimum value of GS is observed in Figure 5 for $[\mathrm{NEr}]=5 \%$, whereas $[\mathrm{NEr}]=6$ and $7 \%$ GS have higher values. This behavior indicates that GS does not follow a monotonically decrease as [NEr] increases. This could be related to a limited solubility of $\mathrm{Er}$ in $\mathrm{TiO}_{2}$ since, due to this effect, $\mathrm{Li}$ and co-workers [17] have reported that for $\mathrm{Er}$ around 3 at $\%$ in $\mathrm{TiO}_{2}$ other phases of $\mathrm{Ti}, \mathrm{O}$ and $\mathrm{Er}$ arise. In our samples no other phases of $\mathrm{TiO}_{2}$ were observed, so probably in our 
case that limit of solubility occurs around [NEr] 5\% (3.3 at\% measured by EDS according to Figure 1) and for [NEr] $>5 \%$ no more Er ions enter into the nanocrystalline lattice of $\mathrm{TiO}_{2}$. For $[\mathrm{NEr}]=6$ and $7 \%$ amorphous material composed by Ti, O, and $\mathrm{Er}$ elements, aside from crystalline $\mathrm{TiO}_{2}: \mathrm{Er}$, can be present into the nanoparticle, as suggested by the broad band observed at low $2 \theta$ values for these two values of [NEr].

The direct $\left(\mathrm{E}_{\mathrm{gd}}\right)$ and indirect $\left(\mathrm{E}_{\mathrm{gi}}\right)$ forbidden energy band gaps of $\mathrm{TiO}_{2}$ :Er nanoparticles were calculated by employing the relation $(\alpha h v)^{\mathrm{n}} \propto\left(\mathrm{h} v-\mathrm{E}_{\mathrm{g}}\right), \mathrm{n}=1 / 2$ for the indirect band gap and $\mathrm{n}=2$ for the direct one. Here, $\alpha$ is the optical absorption coefficient, and hv is the photon energy. Taking into account that under the conditions studied in this work the PA amplitude is directly proportional to $\alpha$, the relation (PA amplitude*hv) $\propto\left(\mathrm{h} v-\mathrm{E}_{\mathrm{g}}\right.$ ) can be employed to calculate $\mathrm{E}_{\mathrm{gd}}$ and $\mathrm{E}_{\mathrm{gi}}$. The top inset in Fig. 5 displays the $E_{g d}$ and $E_{g i}$ versus the nominal concentration of $\mathrm{Er}$, for all the [NEr] values. It can be observed that $\mathrm{E}_{\mathrm{gd}}$ and $\mathrm{E}_{\mathrm{gi}}$ show minima for $[\mathrm{NEr}]=5 \%$, as expected, because the lowest $\mathrm{R}$ is obtained when $[\mathrm{NEr}]=5 \%$. In the bottom inset, $\mathrm{E}_{\mathrm{gd}}$ and $\mathrm{E}_{\mathrm{gi}}$ vs. quadratic inverse of the radius $(R)$ of the particle is plotted. It can be seen that $E_{g d}$ and $\mathrm{E}_{\mathrm{gi}}$ follows the theoretically predicted linear dependence on $\mathrm{R}^{-}$ ${ }^{2}$. This quantum confinement occurs in the weak confinement region, since the Bohr radius of anatase is $0.8 \mathrm{~nm}$ [18]. The solid and dotted lines in the top inset is the result of the $\mathrm{E}_{\mathrm{g}}$ vs. $\mathrm{R}^{-2}$ linear fitting of the $E_{g d}$ and $E_{g i}$ data, respectively. It is important to remark that the undoped $\mathrm{TiO}_{2}$ has experimental $\mathrm{E}_{\mathrm{gd}}$ and $\mathrm{E}_{\mathrm{gi}}$ values very different from the values predicted by the solid line. This suggests that the nanometric character of the $\mathrm{TiO}_{2}$ : Er material, with its respective quantum confinement effects, is mainly originated by the incorporation of $\mathrm{Er}$ in the $\mathrm{TiO}_{2}$ lattice.

The area under the absorption bands, calculated from fitting Gaussian functions, as illustrated in the inset of Figure 4, corresponding to the ${ }^{4} \mathrm{~S}_{3 / 2},{ }^{2} \mathrm{H}_{11 / 2}$, and ${ }^{4} \mathrm{~F}_{3 / 2}$ transitions as a function of nanoparticle radius $(\mathrm{R})$ and as a function of the $[\mathrm{NEr}]$, is plotted in Figure 5 and the inset, respectively. The area under each band is proportional to the number of photons absorbed at around the energy of the transition. The light absorption in these bands improves if [NEr] increases, as expected. However, saturation is observed for larger [NEr] values. Saturation can come from the limited solubility of Er in crystalline $\mathrm{TiO}_{2}$.

On the other hand, as a consequence of the results shown in the inset of Figure 6, the band-area vs. R of Figure 6, maxima absorption values for $R=3$ and $4 \mathrm{~nm}$ are observed, in the three transitions analyzed. If optical absorption is maximum for these $\mathrm{R}$ values, larger light emissions could be expected for $\mathrm{TiO}_{2}:$ Er nanoparticles with radius in the $3-4 \mathrm{~nm}$ interval.

\section{Conclusions}

Reproducible nanocrystalline Er-doped $\mathrm{TiO}_{2}$ was prepared by solgel. The average diameter of the nanoparticles depends on the $\mathrm{Er}$ concentration incorporated into the $\mathrm{TiO}_{2}$ lattice. The Er concentration in the nanocrystalline $\mathrm{TiO}_{2}$ is around $2 / 3$ of the Er nominal concentration in the growing precursor solution. The direct and indirect band gap energies depend on the size of the particle, approximately following the well-known $\mathrm{E}_{\mathrm{g}}$ versus $\mathrm{R}^{-2}$ linear dependence. Photoacoustic spectra evidence the ${ }^{4} \mathrm{I}_{9 / 2},{ }^{4} \mathrm{~F}_{9 / 2},{ }^{4} \mathrm{~S}_{3 / 2}$, ${ }^{2} \mathrm{H}_{11 / 2}$, and ${ }^{4} \mathrm{~F}_{3 / 2}$, electronic transitions of $\mathrm{Er}^{3+}$ ions. Analysis of area under the ${ }^{4} \mathrm{~S}_{3 / 2},{ }^{2} \mathrm{H}_{11 / 2}$, and ${ }^{4} \mathrm{~F}_{9 / 2}$ bands is discussed in terms of the Er concentration in $\mathrm{TiO}_{2}$ nanoparticles.

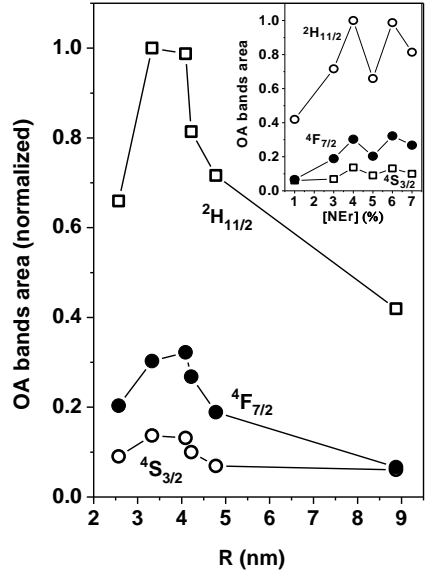

Fig. 6: Normalized Area Under the ${ }^{4} \mathrm{~S}_{3 / 2},{ }^{2} \mathrm{H}_{11 / 2}$, and ${ }^{4} \mathrm{~F}_{9 / 2}$ Transitions $\mathrm{Ab}$ sorption Bands Versus the Radius of the $\mathrm{Tio}_{2}$ : Er Nanoparticles. The Inset Displays the Area Under Bands as A Function of [Ner].

\section{References}

[1] Yan Y, Chaudhuri SR, Chen DG \& Sarkar A (1995), Sol- Gel Synthesis of Titania Thin-Film-Stabilized Porous Silica Coating. $\begin{array}{llll}\text { Chemistry of } & \text { Materials }\end{array}$ http://dx.doi.org/10.1021/cm00059a006.

[2] Gusamano G, Montesperelli G, Nuziante P, Traversa E, Montenero A, Braghini M, Mattogno G \& Bearzotti A (1993), HumiditySensitive properties of Titania Films Prepared using the Sol-Gel Process. Journal of Ceramic Society of Japan 101[9], 1095-1100. http://dx.doi.org/10.2109/jcersj.101.1095

[3] Hamasaki Y, Ohkubo S, Murakami K, Sei H \& Nogami G (1994), Photoelectrochemical Properties of Anatase and Rutile Films Prepared by the Sol-Gel Method. Journal of the Electrochemical Society 141[3], 660-663. http://dx.doi.org/10.1149/1.2054787.

[4] Bahtat A, Bouazaoui M, Bahtat MM, Garapon C, Jacquier B \& Mugnier J (1996), Up-conversion fluorescence spectroscopy in Er3+: TiO2 planar waveguides prepared by a Sol-Gel process. Journal of Non-Crystalline Solids 202, 16-22. http://dx.doi.org/10.1016/0022-3093(96)00172-X.

[5] Huang SY, Kavan L, Exnar I \& Grätzel M (1995), Rocking chair Lithium battery based on nanocrystalline TIO2 (Anatase). Journal of the Electrochemical Society 142, 142-144. http://dx.doi.org/10.1149/1.2048726.

[6] Tomás SA, Stolik S, Palomino R, Lozada R, Persson C, Pepe I, \& Ferreira da Silva A (2005), Influence of rhodamine 6G doping on the optical properties of $\mathrm{TiO} 2$ sol-gel films. Journal of Applied Physics 98, 073516. http://dx.doi.org/10.1063/1.2073972.

[7] Tomás SA, Stolik S, Palomino R, Lozada R, Persson C, Ahuja R, Pepe I, \& Ferreira da Silva A (2005), Optical properties of rhodamine 6G-doped TiO2 sol-gel films. Journal de Physique IV 125, 415-417. http://dx.doi.org/10.1051/jp4:2005125097.

[8] Tomás SA, Palomino R, Lozada R, da Silva Jr EF, de Vasconcelos EA, de Azevedo WM, Persson C, Pepe I, David DGF, \& Ferreira da Silva A (2005), Optical and Electronic Characterization of the Band Structure of Blue Methylene and Rhodamine 6G-doped TiO2 Sol-Gel Nanofilms. Microelectronics Journal 36, 570-573. http://dx.doi.org/10.1016/i.mejo.2005.02.093.

[9] Ferreira da Silva A, Pepe I, Gole JL, Tomás SA, Palomino R, de Azevedo WM, da Siva Jr EF, Ahuja R \& Persson C (2006), Optical properties of in situ doped and undoped titania nanocatalysts and doped titania sol-gel nanofilms. Applied Surface Science 252, 5365-5367. http://dx.doi.org/10.1016/j.apsusc.2005.12.041.

[10] Komuro S, Katsumata T, Kokai H, Morikawa T \& Zhao X (2002), Change in photoluminescence from Er-doped $\mathrm{TiO} 2$ thin films induced by optically assisted reduction. Applied Physics Letters 81, 4733-4735. http://dx.doi.org/10.1063/1.1530733.

[11] Gaponenko NV, Sergev OV, Stepanova EA, Parkun VM, Mudryi AV, Gnaser H, Misiewicz J, Heiderhoff R, Balk LJ, \& Thompson GE (2001), Optical and Structural Characterization of ErbiumDoped TiO2 Xerogel Films Processed on Porous Anodic Alumina. Journal of the Electrochemical Society 148[2], H13-H16. http://dx.doi.org/10.1149/1.1339864.

[12] Anatase: PDF \# 73-1764. Rutile: PDF \# 78-1509. Brookite: PDF \# 76-1936. 
[13] Jeon S \& Braun P (2003), hydrothermal synthesis of Er-doped luminescent $\mathrm{TiO} 2$ nanoparticles. Chemistry of Materials 15, 1256 1263. http://dx.doi.org/10.1021/cm0207402.

[14] Toyoda T \& Tsuboya I (2003), apparent band-gap energies of mixed $\mathrm{TiO} 2 \mathrm{TiO} 2$ nanocrystals with anatase and rutile structures characterized with photoacoustic spectroscopy. Review of Scientific Instruments 74, 782-784. http://dx.doi.org/10.1063/1.1512984.

[15] Kaminskii AA (1990), Laser Crystals: Their Physics and Properties, Springer-Verlag, pp 10. http://dx.doi.org/10.1007/978-3-54070749-3.

[16] Bahtat A, Bouderbala B, Bahtat M, Boauzaoui M, Mugnier J \& Druetta M (2006), Structural characterization of Er3+ doped solgel TiO2 planar optical waveguides. Thin Solid Films 506/507, 5962.

[17] Li J-G, Wang X-H, Kamiyama H, Ishigaki T, \& Sekiguchi T (2006), RF plasma processing of Er-doped $\mathrm{TiO} 2$ luminescent nanoparticles.
Thin
Solid
Films $506 / 507$,
292-296. http://dx.doi.org/10.1016/j.tsf.2005.08.093.

[18] Elim HI, Ji W, Yuwono AH, Xue JM, \& Wang J, (2003), Ultrafast optical nonlinearity in poly(methylmethacrylate) TiO2poly(methylmethacrylate)-TiO2 nanocomposites. Applied Physics Letters 82, 26913693. http://dx.doi.org/10.1063/1.1568544. 